\title{
Blast resilience of composite sandwich panels with hybrid glass-fibre and carbon-fibre skins
}

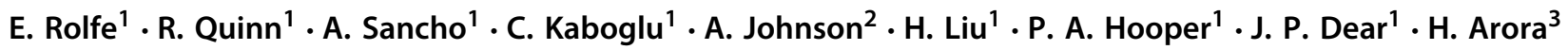

Received: 11 May 2018 / Accepted: 9 July 2018 / Published online: 18 July 2018

(c) The Author(s) 2018

\begin{abstract}
The development of composite materials through hybridisation is receiving a lot of interest; due to the multiple benefits, this may bring to many industries. These benefits include decreased brittle behaviour, which is an inherent weakness for composite materials, and the enhancement of mechanical properties due to the hybrid effect, such as tensile and flexural strength. The effect of implementing hybrid composites as skins on composite sandwich panels is not well understood under high strain rate loading, including blast loading. This paper investigates the blast resilience of two types of hybrid composite sandwich panel against a full-scale explosive charge. Two hybrid composite sandwich panels were mounted at a $15 \mathrm{~m}$ stand-off distance from a $100 \mathrm{~kg}$ nitromethane charge. The samples were designed to reveal whether the fabric layup order of the skins influences blast response. Deflection of the sandwich panels was recorded using high-speed 3D digital image correlation (DIC) during the blast. It was concluded that the combination of glass-fibre reinforced polymer (GFRP) and carbon-fibre reinforced polymer (CFRP) layers in hybrid laminate skins of sandwich panels decreases the normalised deflection compared to both GFRP and CFRP panels by up to 41 and $23 \%$, respectively. The position of the glass-fibre and carbon-fibre layers does not appear to affect the sandwich panel deflection and strain. A finite element model has successfully been developed to predict the elastic response of a hybrid panel under air blast loading. The difference between the maximum central displacement of the experimental data and numerical simulation was ca. $5 \%$ for the hybrid panel evaluated.
\end{abstract}

Keywords Blast $\cdot$ Hybrid composite $\cdot$ Composite sandwich $\cdot$ Digital image correlation

\section{Introduction}

Hybrid composite materials are being widely researched with the aim of introducing pseudo-ductility whilst maintaining the high strength inherent to composites. These properties would be beneficial for many industries, including the naval sector. The naval sector, however, would require large volumes of such hybrid composites within limited time scales. These requirements are best met using composite materials that are already commercially available and can be sim-

\section{E. Rolfe}

emily.rolfe11@imperial.ac.uk

1 Department of Mechanical Engineering, Imperial College London, South Kensington Campus, London SW7 2AZ, UK

2 GOM UK Ltd., 14 The Cobalt Centre, Siskin Parkway East, Coventry CV3 4PE, UK

3 Zienkiewicz Centre for Computational Engineering, College of Engineering, Swansea University, Bay Campus, Swansea SA1 8EN, UK ply hybridised. Composites can be hybridised in three main ways: layer-by-layer (interlaminar), within layers in a weave (intralaminar) and within the yarn (intrayarn) (Swolfs et al. 2014). For interlaminar hybrids, the position of the layers can be tailored to suit expected loads. The ability to tailor such composite materials for an expected load is a major benefit. Naval structures undergo a particularly broad and demanding loading regime, including high strain rate loading, impact, blast loading and wave slamming. It is difficult to predict the response of hybrid composites to such complex loads. The resilience of hybrid composites to these loads must, therefore, be evaluated. Glass-fibre and carbon-fibre reinforced polymers (GFRPs/CFRPs) are widely used in existing naval structures (Kable 2018a, b). Hence, the hybridisation of GFRP and CFRP is investigated in this research.

By hybridising glass fibres and carbon fibres, a number of researchers have successfully increased the failure strain of such hybrid laminates by up to $50 \%$ compared to CFRP laminates (Manders and Bader 1981; You et al. 2007; Naresh et al. 2016). Murugan et al. (2014) fabricated interlaminar 
GFRP/CFRP hybrids and characterised their tensile strength, flexural strength, impact strength and performed dynamic mechanical analysis. This revealed that the stacking sequence of the fabrics has an effect on the flexural properties of the hybrid laminate. Song (2015) also investigated the performance of interlaminar GFRP/CFRP and aramid-fibre/CFRP hybrid composites under tensile and flexural tests. Song concluded that the tensile strength was dominated by the carbon fibres and whether the second fibrous material was glass or aramid made little difference. However, Song agreed that the stacking sequence has an effect on the mechanical properties of the composite laminates.

Research has been performed into the low velocity impact performance of GFRP/CFRP hybrids. Enfedaque et al. (2010) and Sevkat et al. (2009) concluded that the penetration impact resistance of such hybrid laminates can be improved when glass-fibre fabrics were the outermost layers. Under repeated impact test, Sevkat et al. (2010) found that damage build-up and accumulation were reduced when glass-fibre layers were added and especially when glass-fibre layers were added as the outside layers. Researchers in this field widely agree that if fibres with the highest energy absorption are used as the outermost layers, the hybrid laminates are able to absorb more energy (Swolfs et al. 2014). The ability of hybrid composites to exhibit damage contributes directly to the amount of energy they can absorb. Sevkat et al. (2010) showed that the damaged area in GFRP/CFRP hybrids under low velocity impact was greater than the damaged areas in laminates made from either of the constituent composites.

Pandya et al. (2013) have investigated ballistic impact behaviour on hybrid GFRP/CFRP laminates. The authors concluded that for a constant laminate thickness, the ballistic limit was increased by replacing carbon-fibre laminate layers with glass-fibre layers. Furthermore, a higher ballistic limit was achieved when the carbon-fibre layers were placed within the glass-fibre layers. The performance of GFRP/CFRP hybrid laminates under high velocity impact was investigated by Reddy et al. (2017). The proportion of weight of the two fibres was varied and the authors concluded that 50:50 in weight of the fibres demonstrated maximum energy absorption. The ballistic impact performance of glass-fibre/aramid-fibre/carbon-fibre hybrid composite laminates was investigated using a gas gun by Randjbaran et al. (2014). The position of the glass-fibre and carbon-fibre layers was varied to observe the effect this has on energy absorption of the laminate. These experiments revealed that placing a glass-fibre layer at the front, experiencing the impact, is beneficial and a carbon-fibre layer at the rear is detrimental to the panel performance.

The research discussed so far focusses on interlaminar hybrid composite laminates alone. Composite sandwich panels with polymeric foam cores are commonly the structural material of choice within the marine sector. The perfor- mance of such sandwich panels with interlaminar hybrid GFRP/CFRP laminates as skins against blast and shock loading is not well understood. The following paragraph discusses investigations that have been carried out on sandwich panels with alternative hybrid skins under blast and shock loading.

Arora et al. (2012) performed full-scale air blast experiments on a panel with GFRP skins and a panel with CFRP skins. Both panels had an identical styrene acrylonitrile (SAN) foam core and a similar overall areal density. The GFRP panel had a greater out-of-plane displacement and suffered from a large face-sheet crack, whereas the CFRP panel suffered from minor cracks initiating at the bolt holes. Following blast, Arora investigated the edgewise compressive residual strength of sections of the panels (Arora et al. 2014). The results revealed that the percentage drop in strength was greater for the CFRP panel compared to the GFRP panel. The CFRP panels exhibited a lower out-of-plane deflection compared to the GFRP panels under air blast loading. However, further underwater blast testing has revealed that CFRP panels suffer catastrophic brittle failure in this loading regime (Rolfe et al. 2017). This indicates that a panel with solely CFRP skins may not be suitable under all the types of loading experienced by a naval vessel. The performance of a composite sandwich panel with hybrid aramid-fibre and glass-fibre skins was compared to a panel with glass-fibre skins when subjected to underwater blast by Arora (2012). The aramid-fibre/glass-fibre hybrid panel suffered from severe skin cracking. Additionally, this panel did not absorb or redistribute sufficient blast energy and transferred a larger proportion of the blast impulse loading to more core crushing. These results show that the replacement of glass-fibre by aramid-fibre lessened the skin properties rather than enhancing them. This indicates that this combination was not an optimised hybrid.

The addition of interlayers, such as poly-urea (PU) and polypropylene (PP), has been investigated. Tekalur et al. (2008) and Gardner et al. (2012) used a shock tube to load composite sandwich panels with GFRP skins and PU interlayers. Placing the interlayer behind the front skin or behind the core was found to reduce back-skin deflection. Kelly et al. (2015) used GFRP skins and PP interlayers in the front skin of a composite sandwich panel. This panel was subjected to full-scale air blast loading and compared to a panel without the PP interlayers. The panel with PP interlayers deflected less, suffered from less front skin/core debonding and experienced no front skin cracking. These results demonstrate that the PP interlayers improve the integrity of the front skin which may be useful in preventing water ingress following a blast. The underwater blast performance of composite sandwich panels with GFRP skins and poly-urea coatings was investigated by LeBlanc et al. (2013). The panels were subjected to pressures of $10 \mathrm{MPa}$ using a conical shock tube (CST) that produces a shock load equivalent to that of a 
Fig. 1 Experimental design showing: a schematic layup diagram of hybrid composite panels; hybrid 1 (H1a, H1b) and hybrid 2 (H2a, H2b) and b schematic diagram of blast cubicle setup (a)

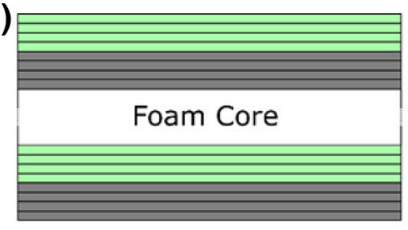
HYBRID-1

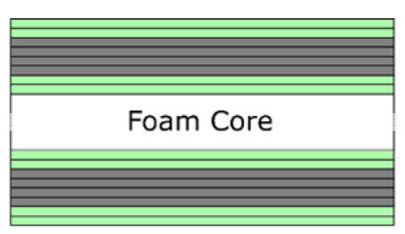

HYBRID-2

Glass-Fibre Ply

Carbon-Fibre Ply (b) Steel Cubicle Composite Panel

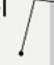
Steel Frame charge detonated underwater. The authors concluded that a thick coating on the back face improved panel response, whereas a thin layer on the front degraded the response. This paper investigates how composite sandwich panels with polymeric foam cores and hybrid GFRP/CFRP skins perform under large-scale explosive blast loading.

\section{Materials}

Four composite sandwich panels tested were constructed from eight ply face-sheets either side of a polymeric foam core. The panels were $1.75 \mathrm{~m} \times 1.55 \mathrm{~m}$ in size. The face sheets were interlaminar glass-fibre/carbon-fibre hybrids with layups as shown in Fig. 1a. Two panels with hybrid 1 layup and two panels with hybrid 2 layup were fabricated. Hybrid 1 had an asymmetrical skin layup which aimed to take advantage of the compressive and tensile properties of glass-fibre and carbon-fibre, respectively. This layup could be advantageous if the direction of loading is known. Hybrid 2 aimed to contain the brittle carbon-fibre layers within the glass-fibre layers, which have a greater elongation and, thus, maintain the integrity of the skin once the stiffer carbon-fibre has fractured. This successfully occurs on a smaller scale (Czél and Wisnom 2013). All panels had a polyvinyl chloride (PVC) foam core with core thickness, $t_{\text {core }}, 30 \mathrm{~mm}$ and density $100 \mathrm{~kg} / \mathrm{m}^{3}$ (Divinycell H100).

\subsection{Face-sheet properties}

The panels had a total of 8 fibre plies in each skin, 4 glass-fibre and 4 carbon-fibre layers arranged quadriaxially $[0 / 90 /-45 /+45]_{2}$ CORE $[+45 /-45 / 90 / 0]_{2}$. The face sheets used biaxial E-glass-fibre, $600 \mathrm{gsm}$, and biaxial carbon-fibre, 400 gsm 12 k HexTow AS4, infused with SR8100 epoxy resin and SD8824 hardener. The panels were fabricated using resin infusion and were ambient cured and then held under vacuum for $24 \mathrm{~h}$ before being demoulded.

\subsection{Experimental method}

Full-scale blast testing was carried out at the DNV GL test site at RAF Spadeadam. The charge size was set at $100 \mathrm{~kg}$ TNT equivalent. Therefore, an appropriate stand-off distance was required to cause sufficient damage to the composite panels yet not damage instrumentation situated behind the panels. An analytical method outlined by Andrews and Moussa (2009) was used to calculate the stand-off distance at which core shear failure, front skin compressive failure and front sheet wrinkling would occur. For this calculation, the Friedlander equation for pressure from a blast was used to calculate maximum pressure at a set stand-off distance. The correction factor of 1.8 was included to take into account how close the charge is to the ground (Smith and Hetherington 1994). Based on the results of these calculations and on previous blast testing performed by Arora et al. (2011) and Kelly et al. (2015), a stand-off distance of $15 \mathrm{~m}$ was selected. The charge was raised to the centre height of the panels, $1.5 \mathrm{~m}$ from the ground by placing it on polystyrene blocks which absorb little blast energy. A large steel plate was situated underneath the polystyrene blocks to prevent cratering of the ground.

During testing, the composite sandwich panels were bolted side-by-side into two steel cubicles, as shown by a schematic diagram in Fig. 1b. $5 \mathrm{~mm}$ thick steel frames were adhered to the front and back of the panels using Sikaflex 291i marine sealing adhesive. The panels were secured to the steel cubicles using $20 \times$ M11 bolts around the perimeter. To prevent the sandwich panel from being crushed upon tightening of the bolts, steel tubes were placed inside the holes in the sandwich panel and sat flush against the front and rear surface of the panel. The steel cubicles were $3.2 \mathrm{~m} \times 3.2 \mathrm{~m}$ with $1.3 \mathrm{~m} \times 1.6 \mathrm{~m}$ openings over which the panels were mounted. A top down schematic view of the experimental setup is shown in Fig. 2.

\subsection{Instrumentation}

To capture the response of the composite panels under blast loading, high-speed images of the rear face-sheet of all panels were recorded. 3D digital image correlation (DIC) was performed on the images to calculate the rear face-sheet displacement and strain. A total of eight high-speed cameras were used, a pair behind each panel, using the same camera setup as previous experiments (Kelly 2016). The camera specifications are detailed in Table 1 . The cameras were trig- 

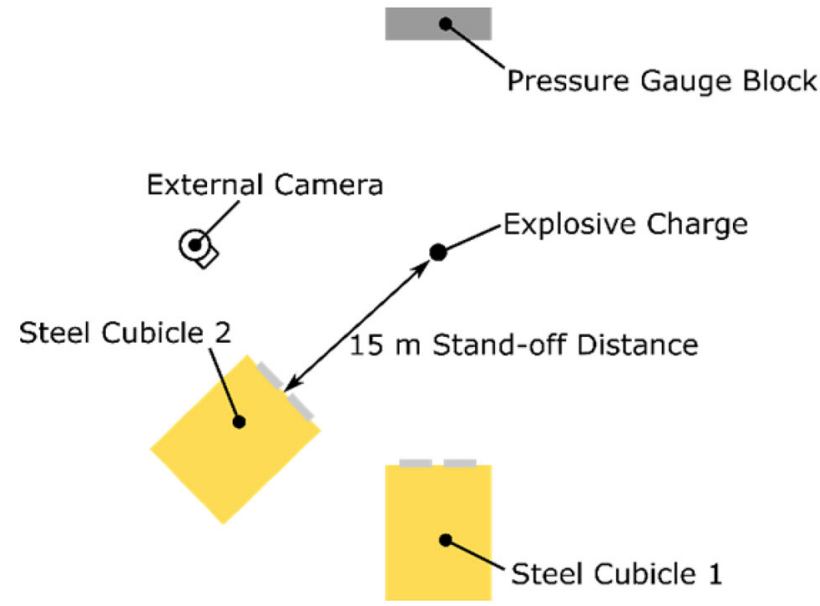

Fig. 2 Top down schematic view of experimental setup

gered by the detonation of the explosion. In addition, one of each hybrid type was instrumented with 14 foil strain gauges on the front skin. Single axis gauges (CEA-06-125UW-350) were positioned in the centre of the panel and along the edges $200 \mathrm{~mm}$ in from the steel frame. A reflected pressure gauge was positioned within a concrete pressure block at the same stand-off distance from the charge as the targets.

\section{Results}

Figure 3a shows a sequence of images of the out-of-plane displacement and major strain for panel H1a at intervals of time calculated from DIC of the high-speed camera images. The major strain reaches a maximum at the centre, of $0.70 \%$, sooner than the displacement reaches a maximum. The remaining high strain on the right-hand side of the panel in the final two images, which reaches $0.54 \%$, indicating permanent damage to the panel following blast loading. Figure $3 \mathrm{~b}$ shows the displacement of the horizontal cross-section at the mid-plane of H1a at discrete intervals of time from zero displacement to maximum displacement. This cross-section experiences the greatest deflection. Figure $3 \mathrm{c}$ shows the return phase of this horizontal cross-section. In Fig. 3c, the asymmetrical return of the panel, highlighted in the final four displacement images in Fig. 3a, can be seen in an alternative visualisation. The damage to the panel is prominent in this return stroke with gradient discontinuities and deceleration of the panel shown where deflection lines are closer together. Panel H1a experiences a maximum central displacement of $74.6 \mathrm{~mm}$. Figure $4 \mathrm{a}$ shows the outof-plane displacement and major strain image sequences for panel H1b calculated from high-speed DIC. The displacement of the horizontal cross-section at the mid-plane of $\mathrm{H} 1 \mathrm{~b}$, as shown in Fig. 4b, is similar to that of H1a. Figure 4c shows the return stroke of this cross section. The gradient discontinuities indicate that there is permanent damage on both the right-hand side and left-hand side of the panel. The maximum displacement of $\mathrm{H} 1 \mathrm{~b}$ is $72.8 \mathrm{~mm}$ and maximum central strain is $0.67 \%$. Maximum strain was reported with a difference of $0.03 \%$ and maximum displacement with a difference of $1.8 \mathrm{~mm}$ for these panels both fabricated with hybrid 1 skins.

Figure 5a shows the DIC image series for out-of-plane displacement and major strain for panel H2a. Figure 5b shows the displacement of the horizontal cross section at the midplane of $\mathrm{H} 2 \mathrm{a}$ at discrete time intervals from zero displacement to maximum displacement. The maximum displacement of the central point is $72.8 \mathrm{~mm}$. The return phase of this horizontal cross section is shown in Fig. 5c. The asymmetrical return of the panel can be seen and, once again, correlates with the DIC image sequence in Fig. 5a. The panel experiences a maximum central strain of $0.70 \%$. Figure $6 a$ shows the sequence of images of the out-of-plane displacement and major strain for panel $\mathrm{H} 2 \mathrm{~b}$. The remaining high strain, $0.69 \%$, on the lefthand side of the panel in the final three images indicates permanent damage to the panel following blast loading. Figure $6 \mathrm{~b}$ shows the out-of-plane displacement of the horizontal cross section at the mid-plane of $\mathrm{H} 2 \mathrm{~b}$; this cross-section experiences the greatest deflection. In Fig. 6a, b, sharp changes in deflection gradient as seen one quarter of the way across the panel width indicate damage to the panel. Maximum central displacement reached by this panel is $72.8 \mathrm{~mm}$. The return stroke of this cross section is shown in Fig. 6c. The maximum central strain experienced by panel $\mathrm{H} 2 \mathrm{~b}$ is $0.65 \%$. The hybrid 2 panels showed no difference in central maximum displacement and a $0.05 \%$ difference in central maximum strain.

Figure 7a shows a plot of the incident blast pressure along with the displacement of the centre points of all four panels tested. The pressure reaches a maximum of $218 \mathrm{kPa}$ before
Table 1 Details of the camera models and frame rate for each panel

\begin{tabular}{llllc}
\hline Panel number & Hybrid type & Camera 1 & Camera 2 & Frame rate (fps) \\
\hline H1a & Hybrid 1 & SA1.1 mono & SA5 mono & 4000 \\
H1b & Hybrid 1 & SA1.1 colour & SA5 colour & 4000 \\
H2a & Hybrid 2 & AX100 & AX100 & 4000 \\
H2b & Hybrid 2 & SAX2 & SAX2 & 12,000 \\
\hline
\end{tabular}




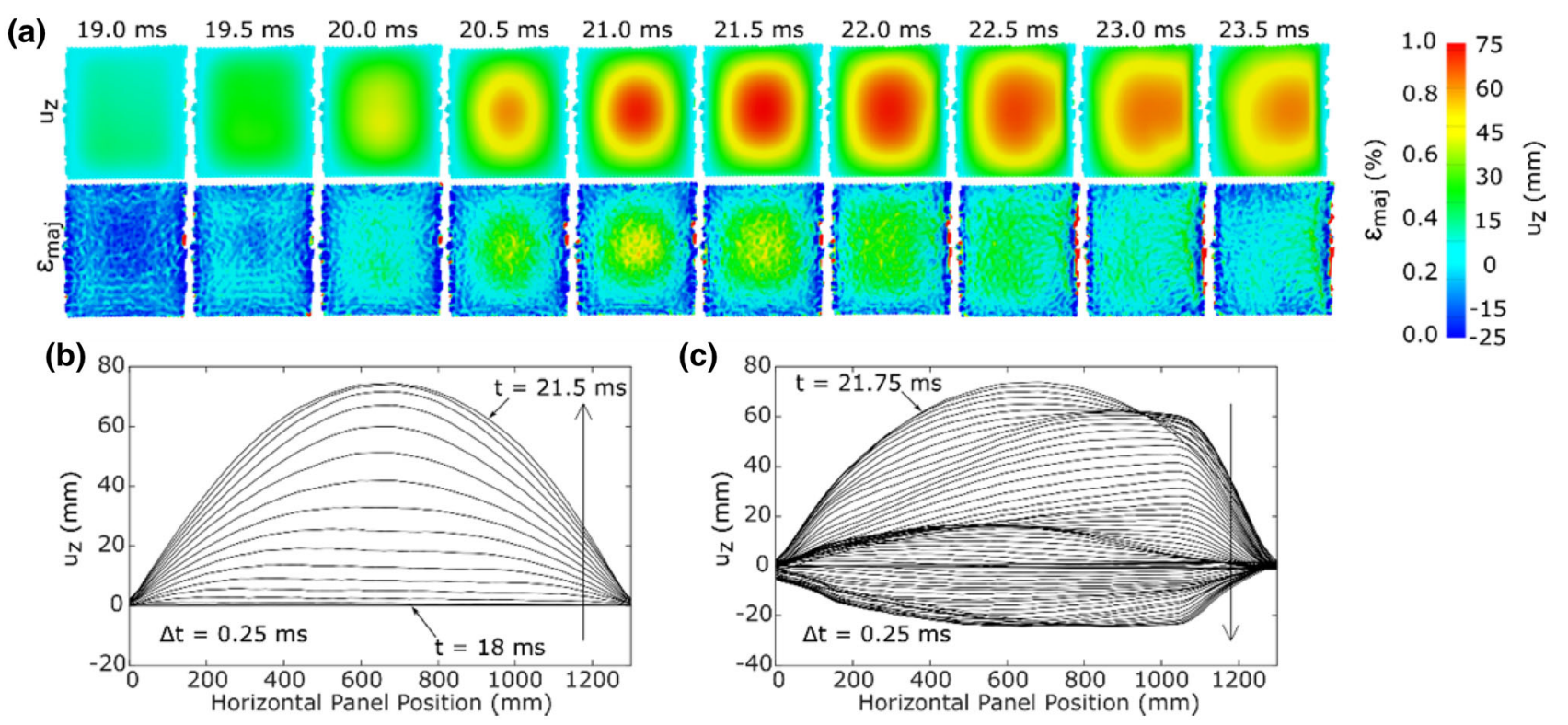

Fig. 3 DIC results for panel H1a showing: a out-of-plane displacement and major strain images, b deflection at time intervals for the horizontal centre section and $\mathbf{c}$ rebound at time intervals for the horizontal centre section
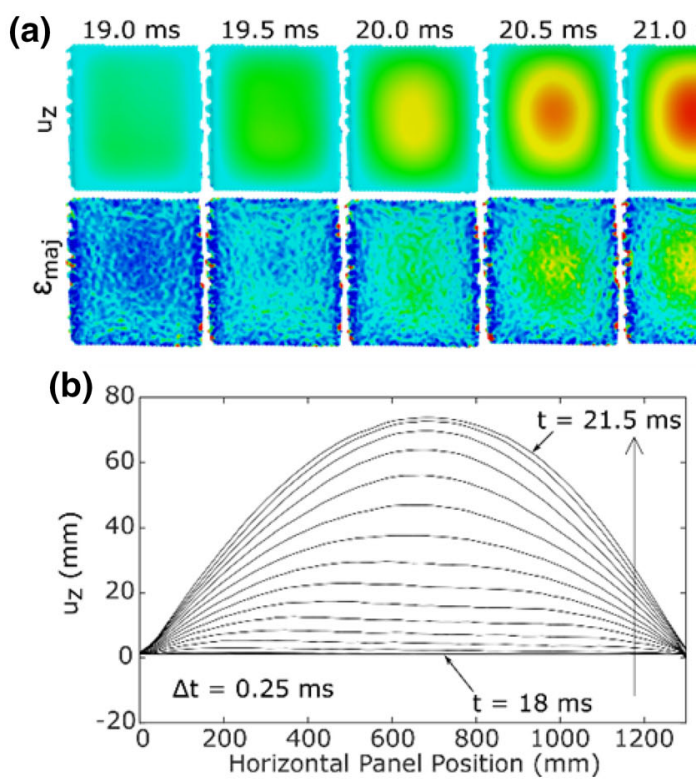

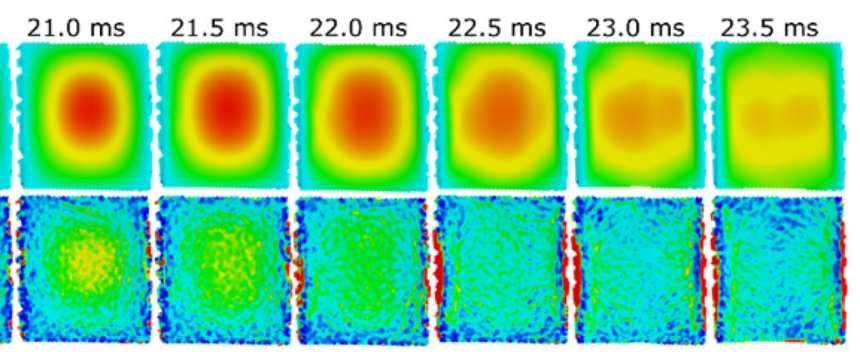

(c)

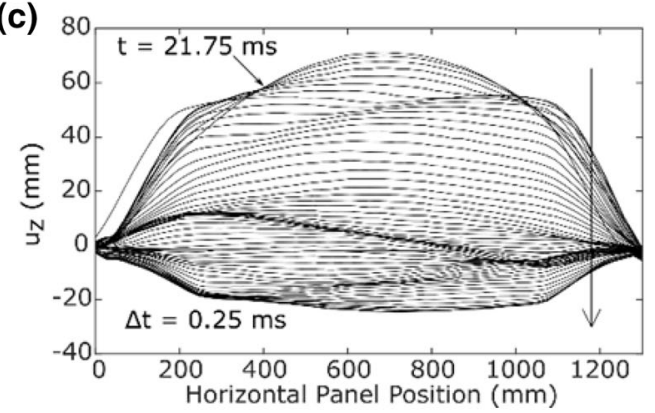

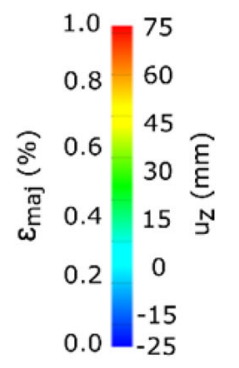

Fig. 4 DIC results for panel H1b showing: a out-of-plane displacement and major strain images, b deflection at time intervals for the horizontal centre section and $\mathbf{c}$ rebound at time intervals for the horizontal centre section

slowly reducing to zero. The panels demonstrate similar peak deflection and maximum rebound. The changes in gradient of the return strokes are caused by the damage suffered by the panels. During the blast event, both types of hybrids have a similar overall behaviour, including deflection and major strain. Figure $7 \mathrm{~b}$ shows the DIC frame at maximum deflection, $21.5 \mathrm{~ms}$, for all four composite sandwich panels.

Two panels, H1a and $\mathrm{H} 2 \mathrm{~b}$, were instrumented with strain gauges on the front skins to understand the panel response. Figure 8 shows the strain recorded at the centre of panel
H1a using a strain gauge on the front skin versus the strain recorded on the rear skin using DIC. The rear skin $y$-direction strain from DIC data peaks at $0.57 \%$ at $21 \mathrm{~ms}$ after detonation. The front skin strain recorded by the strain gauge initially experiences oscillations as it is more sensitive than DIC. When the panel deflects under the blast load from $19 \mathrm{~ms}$ onwards, the front skin experiences compression as the front skin strain is largely negative. This compressive strain peaks at $-2.47 \%$ at $22.64 \mathrm{~ms}$ after detonation. The panel then rebounds resulting in tensile strain on the front skin, reaching 


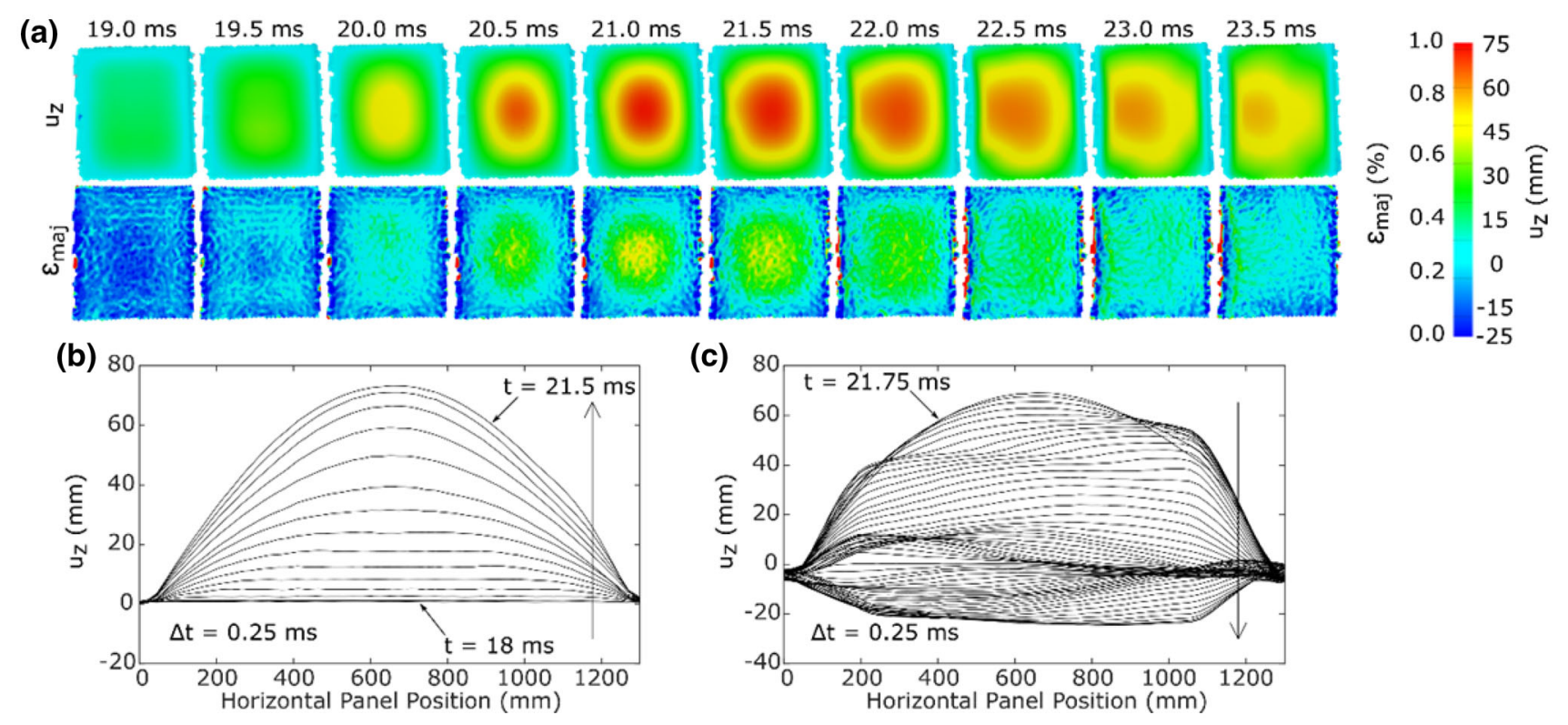

Fig. 5 DIC results for panel H2a showing: a out-of-plane displacement and major strain images, b deflection at time intervals for the horizontal centre section and $\mathbf{c}$ rebound at time intervals for the horizontal centre section

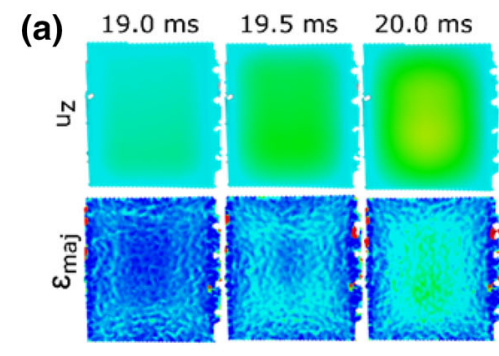

(b)

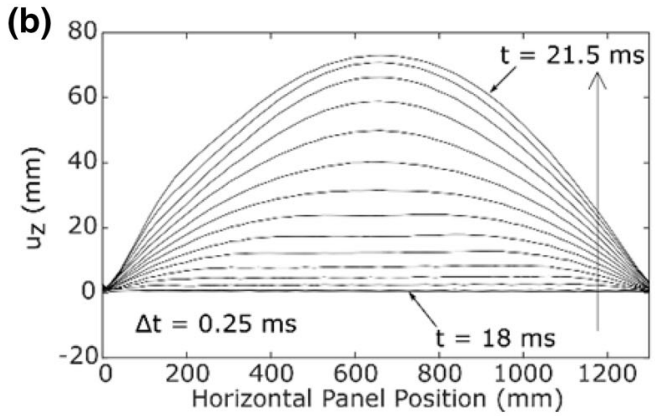

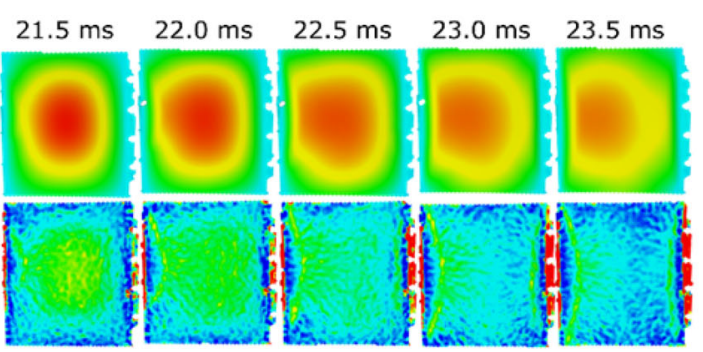

(c)
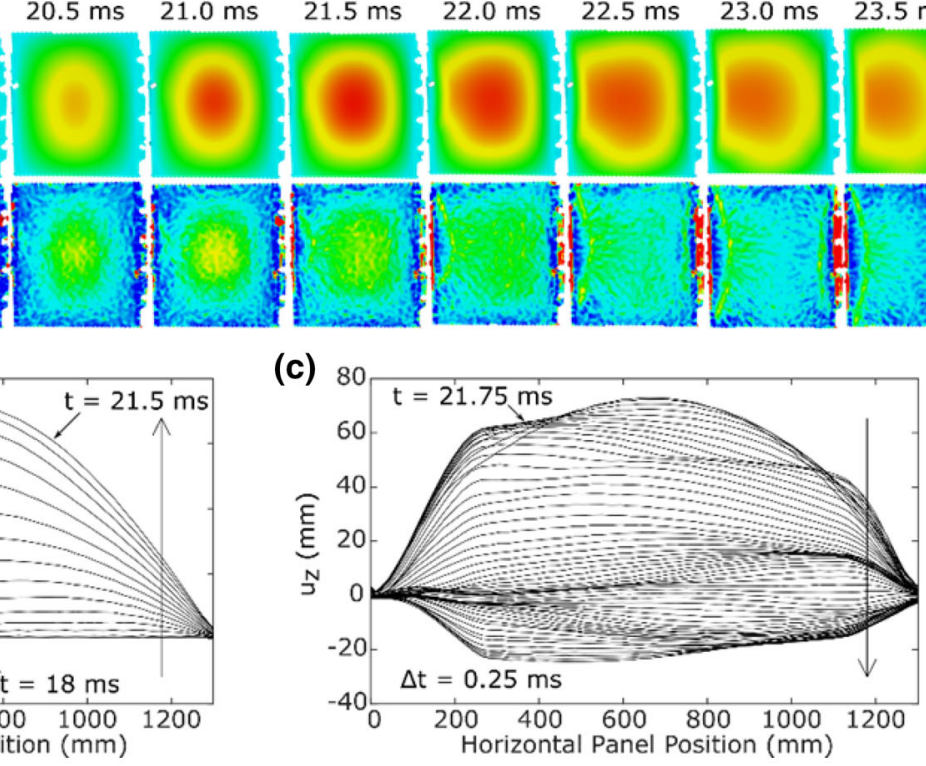

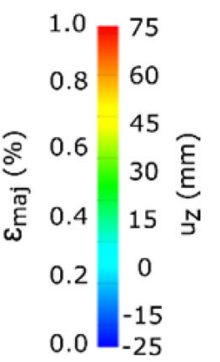

Fig. 6 DIC results for panel H2b showing: a out-of-plane displacement and major strain images, b deflection at time intervals for the horizontal centre section and $\mathbf{c}$ rebound at time intervals for the horizontal centre section

a maximum of $1.69 \%$, and the rear skin goes into compression with a small magnitude of $-0.07 \%$. Both skins experience tension during the transition. This indicates that the panel experiences stretching. The strain gauges revealed that the front skins experience a far greater strain than the rear skins. Figure 9 shows the comparison of front skin strain for the two instrumented panels at four locations on the front skin. The strain readings clearly demonstrate that the panel is not supported equally around the perimeter due to the steel cubicle design. This accounts for the asymmetric response of the panels, particularly during rebound. The central column between the two panels offers less resistance and experiences the greatest loading during blast as the blast clears the edges. The central column, therefore, deflects itself due to blast loading and this has been identified previously (Arora 2012). Hence, the strain gauges along the centre edges of the panels record lower strain readings. The outer edges experience strain up to twice the magnitude, $-5.74 \%$, due to the greater constraint imposed by the stiffer edge of the steel cubicle. Although the magnitude of strain experienced by the front 


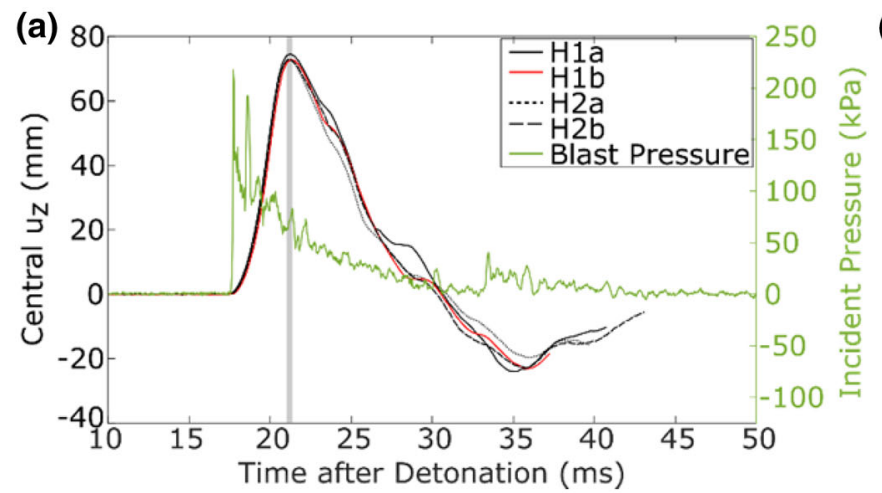

(b)

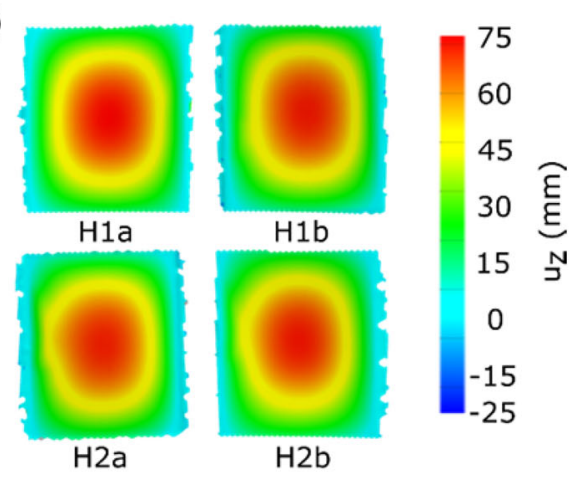

Fig. 7 DIC results showing: a central out-of-plane displacement against time for the four composite sandwich panels along with the recorded incident blast pressure against time and $\mathbf{b}$ maximum deflection image frame at $21.5 \mathrm{~ms}$ for the four composite sandwich panels
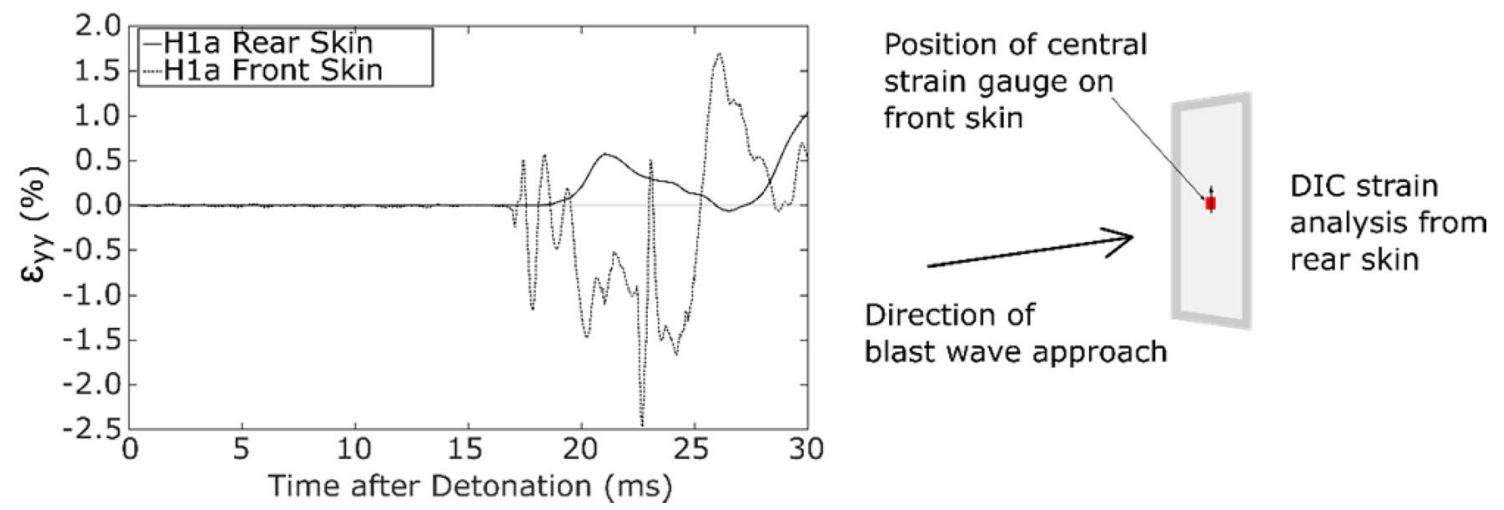

Fig. 8 Central major strain taken from DIC data for the rear skin and strain gauge data for the front skin

and rear skin is different, the spatial strain variations correlate. Figure 10 shows plots of the areal minimum, maximum and average in the region of the strain gauge, taken from DIC data, against the front strain gauge data for panel H1a. The DIC and strain gauge data generally agree in terms of deflection time. The rear skin experiences tension and front skin compression with the skins returning to zero strain at a similar time before deflecting again. The strain gauge readings on the panel left-hand side, the outer edge of the cubicle, show high strain readings after $22 \mathrm{~ms}$ post-detonation. This correlates with the DIC areal maximum strain readings which remain high compared to other areas of the panel. There are low gauge and DIC strain readings near the top and bottom of the panel. The DIC strain at the centre of the panel shows a clear peak and return to near zero which correlates with the strain gauge reading. Furthermore, regions of high strain during panel rebound, visible particularly in Figs. 3a, 5a and $6 \mathrm{a}$, correspond to the outer cubicle edge. The DIC data from the rear face can, therefore, reliably be used to comment on spatial strain variations experienced by the whole panel. The DIC images are as viewed from behind the panel hence are the opposite of the strain gauge readings shown in Figs. 9 and 10 .
Table 2 shows details from the experiment described in this research along with details from a previous blast experiment carried out by the research group (Arora et al. 2012). This previous experiment used the same charge at $14 \mathrm{~m}$ stand-off distance against a GFRP and a CFRP panel with $25 \mathrm{~mm}, 100$ $\mathrm{kg} \mathrm{m}^{-3}$ styrene acrylonitrile (SAN) cores. The performance of the two sets of panels is compared to determine whether hybrid composite skins offer advantages during blast loading. The deflection and strain normalised by the maximum incident pressure for each experiment along with the deflection normalised by the core thickness are detailed in the final three columns of Table 2. For both the hybrids, these three values are lower than for the panels with just GFRP and just CFRP skins. This indicates that the added stiffness of carbon-fibre layers in the face sheets significantly reduces both deflection and strain compared to a GFRP panel. In addition, the hybrid skins reduce the deflection compared to a CFRP panel and achieve comparable levels of strain. During the blast, the hybrid panels demonstrate a clear reduction in deflection. 


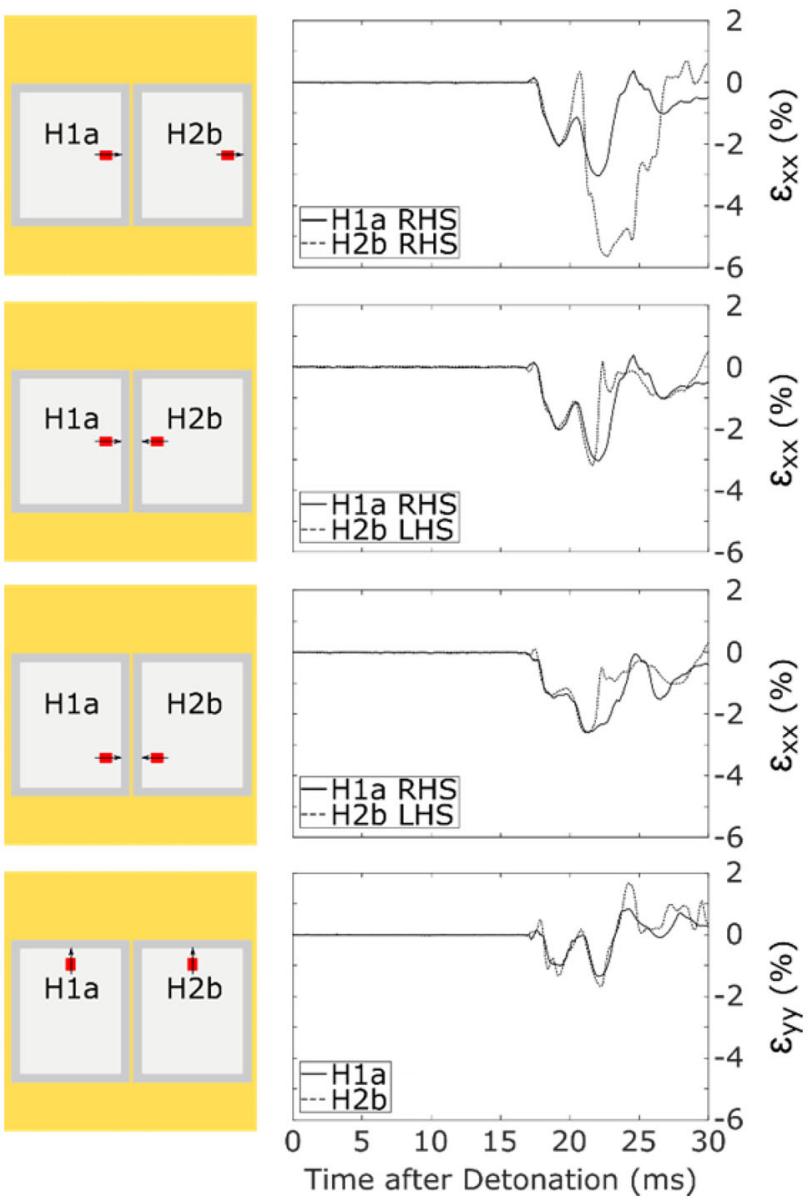

Fig. 9 Comparison of strain gauge readings at different locations across panels $\mathrm{H} 1 \mathrm{a}$ and $\mathrm{H} 2 \mathrm{~b}$

\section{Numerical simulation}

\subsection{Material properties}

The sandwich panels tested in this work were manufactured using glass-fibre/epoxy, carbon-fibre/epoxy and PVC foam. The glass and carbon fabrics used in the composite skins consist of two orthogonal unidirectional plies, which were stitched by texturised polyester threads, shown in Fig. 11. The elastic and interfacial properties of the stitched glass fabric and stitched carbon fabric reinforced composite plies were estimated for numerical simulations based on (Benzeggagh and Kenane 1996; Vaidya and Sun 1997; Salvi et al. 2008; Tan et al. 2015). The average values of the carbon/carbon and glass/glass interface properties, such as stiffness and strength, were used for the glass/carbon interface. The glass/foam and carbon/foam interface strengths were deemed to be equal to the strength of the foam (Lim et al. 2004; Rizov et al. 2005). The estimated material properties for the stitched glass fabrics/epoxy, stitched carbon fabrics/epoxy and PVC foam are shown in Table 3.

\subsection{Finite element model}

A finite element model was developed in Abaqus 2017 to capture the elastic response of the sandwich panels under air blast loading, as shown in Fig. 12a. Corresponding to the physical experimental setup, steel frames with a thickness of $5 \mathrm{~mm}$ were adhered on the front and rear face of the sandwich panels, which were subsequently mounted on the openings of the steel cubicle. The sandwich panel, which included two hybrid skins (each with eight layers of glass-fibre/epoxy and eight layers of carbon-fibre/epoxy) and one foam core, was modelled using C3D8R elements. All the interfaces within the sandwich structures were modelled using the Abaqus inbuilt cohesive surface model (Dassault Systèmes 2012). An estimated preload of $9 \mathrm{kN}$ (about $0.3 \mathrm{MPa}$ ) was exerted on the front steel frame to represent the screwed pressure of the bolts, as shown in Fig. 12b. The air blast load on the sandwich panels was implemented as a time-dependent pressure using the tabular function in Abaqus. The general contact algorithm was used for global contact and a friction coefficient of 0.2 was used for the steel/composite contact surface (Falzon et al. 2017; Liu et al. 2018).

The H1a panel was taken as an example to show the comparison between the experimental and numerical results. The simulation was completed using 32 CPUs on a Linux Cluster with a run time of between 6 and $30 \mathrm{~h}$, depending on the element size.

\subsection{Comparison between experimental and numerical results}

\subsubsection{Central deflection}

Simulations were conducted at different element sizes, including $100 \mathrm{~mm} \times 100 \mathrm{~mm}, 50 \mathrm{~mm} \times 50 \mathrm{~mm}, 25 \mathrm{~mm} \times 25$ $\mathrm{mm}$ and $10 \mathrm{~mm} \times 10 \mathrm{~mm}$. The maximum central deflections obtained from different finite element models were compared in Fig. 13a. The results showed that both the $25 \mathrm{~mm}$ model and $10 \mathrm{~mm}$ model demonstrated good agreement with the experimental results. To increase the computational efficiency and also ensure the simulation quality, the element size of $25 \mathrm{~mm} \times 25 \mathrm{~mm}$ was selected for the simulation. The central deflection versus time after detonation curves obtained from the experiment (H1a-Experiment) and simulation (H1a-Simulation01) were compared and are shown in Fig. 13b. As stated previously, the developed model is an elastic model, which has focused on capturing the elastic response of the sandwich panels subject to the air blast loading. Therefore, the structure response after the peak load was not discussed in the numerical results. The experimental and numerical maximum central deflection is 74.6 and $70.6 \mathrm{~mm}$, respectively, which has a difference of ca. $5 \%$, and the respective peak time is 22 and $22.3 \mathrm{~ms}$, respectively. 

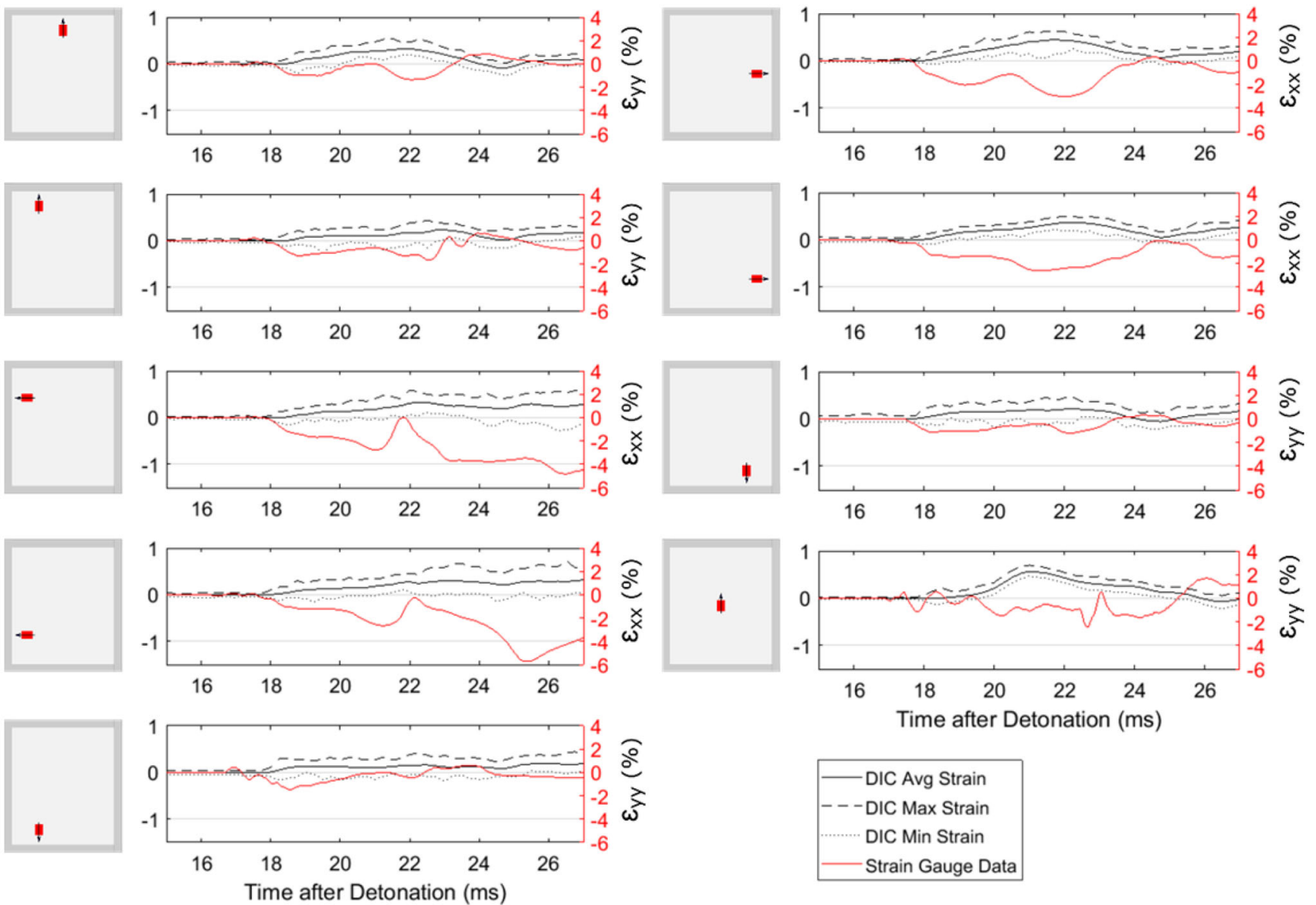
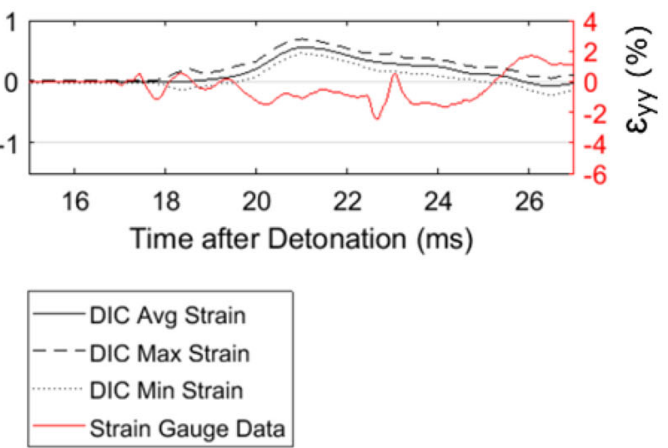

Fig. 10 Comparison of DIC strain and strain gauge readings at different locations across panels H1a

Table 2 Hybrid composite panel experimental results versus GFRP and CFRP panel experimental results

\begin{tabular}{|c|c|c|c|c|c|}
\hline Panel code & Description & $\begin{array}{l}\text { Incident } P_{\max } \\
(\mathrm{kPa})\end{array}$ & $\begin{array}{l}U_{\mathrm{z} \max } / t_{\text {core }} \\
(\mathrm{mm} / \mathrm{mm})\end{array}$ & $\begin{array}{l}U_{\mathrm{z} \max } / P_{\max } \\
(\mathrm{mm} / \mathrm{kPa})\end{array}$ & $\begin{array}{l}\varepsilon_{\text {maj max }} / P_{\text {max }} \\
\left(\mathrm{kPa}^{-1}\right)\end{array}$ \\
\hline H1a & $\begin{array}{l}2 \mathrm{~mm} \text { hybrid skins } \\
30 \mathrm{~mm} \text { PVC core }\end{array}$ & 218 & 2.49 & 0.34 & $3 \times 10^{-5}$ \\
\hline $\mathrm{H} 1 \mathrm{~b}$ & $\begin{array}{l}2 \mathrm{~mm} \text { hybrid skins } \\
30 \mathrm{~mm} \text { PVC core }\end{array}$ & 218 & 2.43 & 0.33 & $3 \times 10^{-5}$ \\
\hline $\mathrm{H} 2 \mathrm{a}$ & $\begin{array}{l}2 \mathrm{~mm} \text { hybrid skins } \\
30 \mathrm{~mm} \text { PVC core }\end{array}$ & 218 & 2.43 & 0.33 & $3 \times 10^{-5}$ \\
\hline $\mathrm{H} 2 \mathrm{~b}$ & $\begin{array}{l}2 \mathrm{~mm} \text { hybrid skins } \\
30 \mathrm{~mm} \text { PVC core }\end{array}$ & 218 & 2.43 & 0.33 & $3 \times 10^{-5}$ \\
\hline $\mathrm{G} 25 \mathrm{~b}^{\mathrm{a}}$ & $\begin{array}{l}2 \mathrm{~mm} \text { GFRP skins } \\
25 \mathrm{~mm} \text { SAN core }\end{array}$ & 250 & 5.60 & 0.56 & $6 \times 10^{-5}$ \\
\hline $\mathrm{C} 25 \mathrm{~b}^{\mathrm{a}}$ & $\begin{array}{l}2 \mathrm{~mm} \text { CFRP skins } \\
25 \mathrm{~mm} \text { SAN core }\end{array}$ & 250 & 4.28 & 0.43 & $3 \times 10^{-5}$ \\
\hline
\end{tabular}

${ }^{a}$ Note that GFRP and CFRP experimental results are taken from Arora (2012)
These results confirm that the proposed numerical model has the capability to predict the elastic behaviour of the sandwich panel under air blast loading. To evaluate the effects of the cohesive surface solution on the compliance of composite sandwich structures, the curve (H1a-Simulation02) obtained from the numerical model without cohesive surface solution was also presented in Fig. 13b to compare with the curve (H1a-Simulation01) obtained from the model with the cohesive surface solution. As expected, the numerical model without the cohesive surface solution delivered higher stiffness and peak load than the one with cohesive surface solution. 


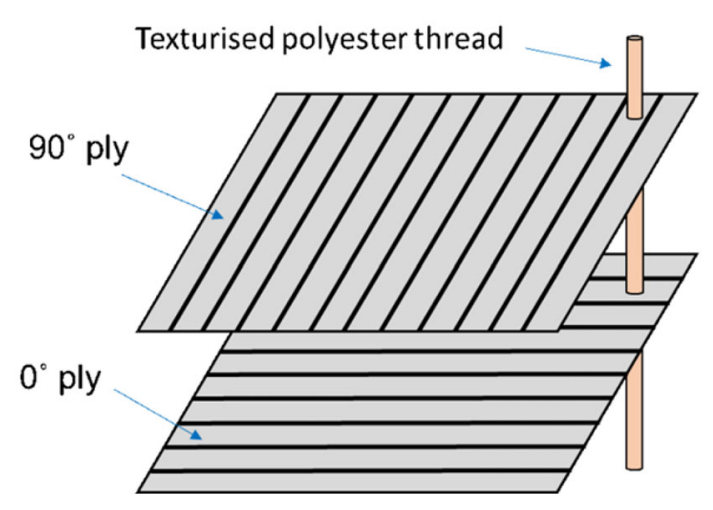

Fig. 11 Schematic of stitched glass-fibre and carbon-fibre fabrics

The panel deflection obtained from simulation was compared with that obtained from the experiment and is shown in Fig. 14. In both the experiment and simulation, the maximum central deflection was observed around $22 \mathrm{~ms}$. Good agreement was obtained between the experimental and computational results.

\subsubsection{Major strain}

In the experiment, the major strain evolution of the H1a panel was recorded using a high-speed DIC system and is shown in Fig. 3a. Frames showing the evolution of major strain prior to the peak load for the experimental results were selected and shown in Fig. 15. Alongside this, the corresponding numerical results are shown. The experimentally measured major strain and the computational major strain are 0.70 and $0.62 \%$, respectively. Both the strain evolution and maximum strain of the H1a panel in the elastic stage were well reproduced in the numerical simulation. The intention is to follow up this research with an understanding of damage development with Professor Brian Falzon at Queen's University Belfast (Falzon and Apruzzese 2011a, b).

\section{Discussion}

This comparative study was performed to reveal the difference in behaviour between composite sandwich panels with

Table 3 Material properties of the stitched glass fabric/epoxy ply, stitched carbon fabric/epoxy ply and PVC foam core for

\begin{tabular}{llll}
\hline Material & Stitched glass ply & Stitched carbon ply & PVC foam \\
\hline Young's moduli (GPa) & $E_{11}=E_{22}=22.3$ & $E_{11}=E_{22}=67.95$ & $E_{11}=E_{22}=E_{33}=0.125$ \\
& $E_{33}=7.2$ & $E_{33}=7.9$ & \\
Shear moduli (GPa) & $G_{12}=3.9$ & $G_{12}=3.6$ & $G_{12}=G_{13}=G_{23}=0.052$ \\
& $G_{13}=G_{23}=3.2$ & $G_{13}=G_{23}=3.3$ & \\
Poisson's ratio & $v_{12}=0.14$ & $v_{12}=0.04$ & $v_{12}=v_{13}=v_{23}=0.32$ \\
& $v_{13}=v_{23}=0.48$ & $v_{13}=v_{23}=0.33$ & \\
Interface stiffness & $1.0 \times 10^{5}$ & $4.9 \times 10^{5}$ & N/A \\
Cohesive strength (MPa) & $\sigma_{\mathrm{I}}=15 ; \sigma_{\mathrm{II}}=25$ & $\sigma_{\mathrm{I}}=17 ; \sigma_{\mathrm{II}}=30$ & $\sigma_{\mathrm{I}}=3 ; \sigma_{\mathrm{II}}=4$ \\
Ply thickness $(\mathrm{mm})$ & 0.6 & 0.4 & 30 \\
\hline
\end{tabular}

(a)

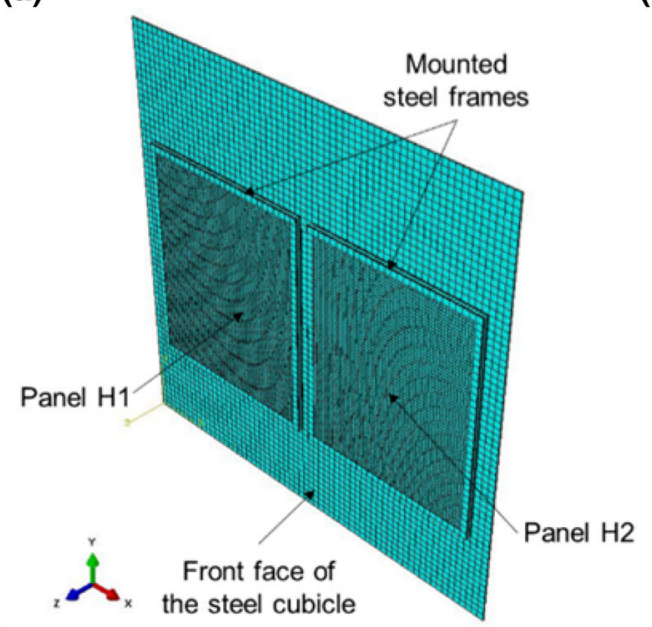

(b)

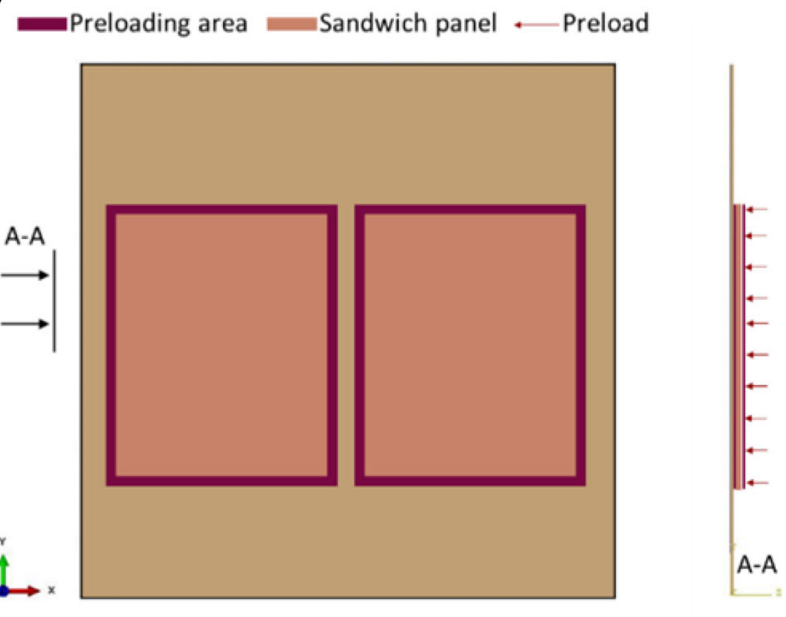

Fig. 12 Finite element model showing: a mesh for the air blast simulation and $\mathbf{b}$ illustration of preload on the front steel frame 

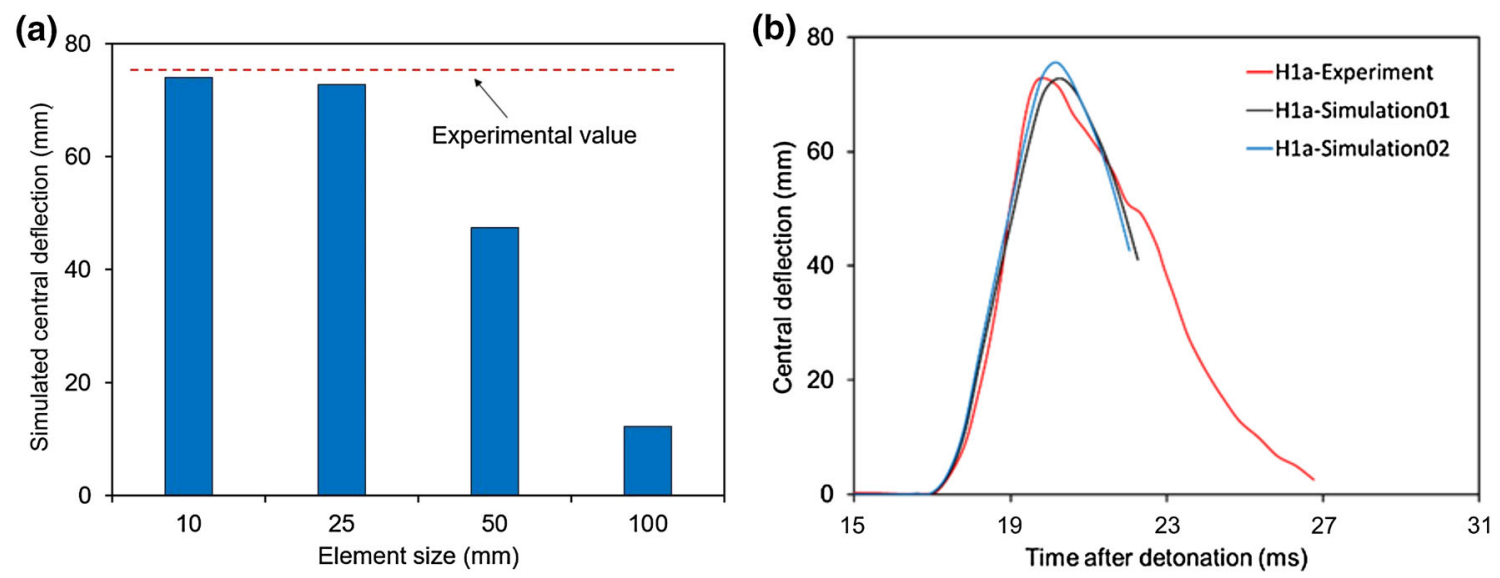

Fig. 13 Finite element model results showing: a mesh sensitivity investigations and $\mathbf{b}$ comparison of central out-of-plane displacement against time obtained from experimental data and simulation data for panel H1a

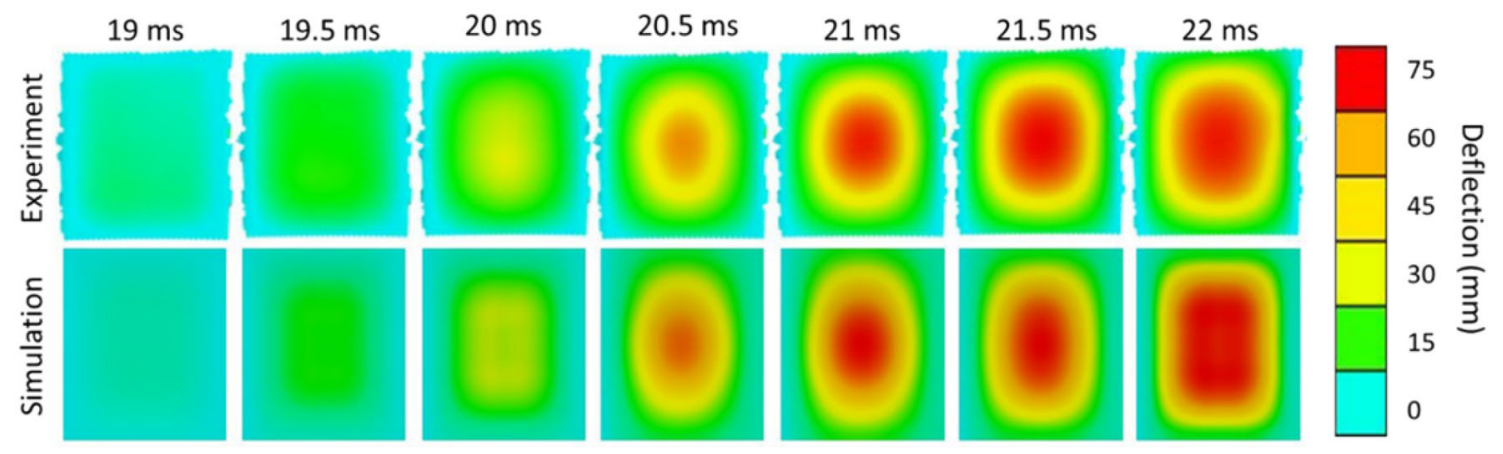

Fig. 14 Evolution of the deflection profile of panel H1a obtained from experimental data and numerical simulation

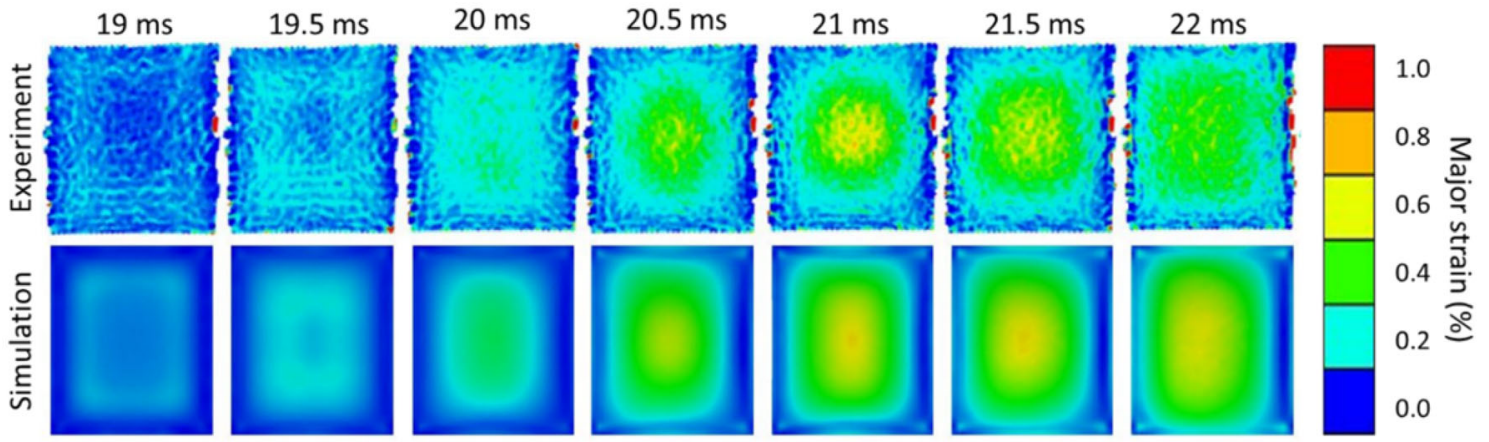

Fig. 15 Evolution of the major strain profile of panel H1a obtained from experimental data and numerical simulation

two types of interlaminar hybrid face-sheets. The panels had the same $30 \mathrm{~mm}$ PVC foam core and the same areal density. The results showed that all four panels demonstrate similar behaviour under blast loading including deflection and rebound. In addition, the DIC data for all panels showed that they experienced internal damage at one quarter and three quarters along the horizontal cross section. None of the panels showed visible skin damage immediately after the blast.

When the performance of the hybrid panels is compared to a similar previous experiment (Arora et al. 2012), it is clear the hybrid skins are advantageous. When the deflection is normalised by either core thickness or blast pressure, the hybrid panels demonstrate a reduced normalised deflection compared to both the GFRP panel and CFRP panel. The value of $U_{\mathrm{z} \text { max }} / t_{\text {core }}$ for the GFRP panel is 5.60, whereas the value for the hybrid panels is less than half this value at a maximum of 2.49. The hybrid skins were implemented to increase the amount of energy that can be absorbed during blast loading. This is achieved either by encouraging damage within the skins, caused by incompatibility between the glass-fibre and 
carbon-fibre properties or by tailoring the layup and utilising the optimal properties of each fibre type. Future analysis will be conducted to determine which process causes their improved performance and whether either process is more detrimental to post-blast strength.

Under previous small-scale impact, these hybrids have been shown to exhibit different deflections and strains (Rolfe et al. 2018). This is because under the impact experiment, the panels experience a localised load at a higher velocity. Due to the localised loading, the front skin, core and rear skin are engaged independently. In addition, the projectile punctured the front skin of the panels and the core. Through this mechanism, the skin and core absorb energy yet the load remains localised as the panel does not distribute load through bending. Different deflections and strains may have been exhibited because the front skins were often perforated and hence tested to a more extreme extent and in some cases until failure. Under large-scale blast loading, the pressure load is more uniform across the panel and it, therefore, responds globally on a large scale. Under these circumstances, the skin layups and core are engaged simultaneously in the global bending response. Although there is certainly damage within the skins, the skins were not tested until final failure unlike the impact experiments. Under blast loading the presence, and hence interactions, of both types of fibres is the key factor rather than the position of each fibre fabric layer.

The strain gauge and DIC data have revealed the difference in strain experienced by the front and rear skins along with the non-uniformity of the boundary conditions. The front skins experience a greater strain magnitude confirming that the foam core plays a major role in energy absorption through elastic compression and damage mechanisms. To record the boundaries, the inside front of the test cubicles was speckled and the cameras were placed such that this was in the field of view. The motion of the cubicle was subsequently removed from the DIC analysis. Although the non-uniform rigidity of the cubicle front is visible from the asymmetric displacement of the panels and variation in strain, the movement of the boundaries has been recorded and can be built into modelling and analysis of the problem.

A finite element model was developed to capture the elastic response of the composite sandwich panels until peak deflection under air blast loading. The sandwich panels were modelled using C3D8R elements with an element size of $25 \mathrm{~mm} \times 25 \mathrm{~mm}$. The maximum central displacement of the experimental results and numerical simulation differed by ca. $5 \%$, and the peak displacements were reached at 22 and $22.3 \mathrm{~ms}$, respectively. The central point major strain measured experimentally was $0.70 \%$ and numerical model reached a maximum of $0.62 \%$. Overall, the deflection profile and major strain profile obtained from experimental data and numerical simulation agreed well.

\section{Conclusions}

Composite sandwich panels with hybrid glass-fibre and carbon-fibre skins were studied under full-scale blast loading. These experiments have demonstrated the ability of simple hybrid composite sandwich panels to resist full-scale blast loads and offer advantages over panels with fully GFRP or CFRP skins. In addition, the position of the glass-fibre and carbon-fibre fabric layers was shown to have no effect on the panel response. The key factor is the presence of both fabric types. The following bullet points summarise the main findings from the research:

- A combination of glass-fibre and carbon-fibre layers in laminate skins of sandwich panels decreases the deflection compared to GFRP or CFRP panels when normalised by blast or panel thickness parameters.

- Under large-scale blast loading, where the pressure load is approaching uniformity across the panel, the position of the glass-fibre and carbon-fibre layers does not appear to affect the sandwich panel deflection and strain.

- Implementation of strain gauges on panels during blast loading has revealed that front skins experience a greater magnitude of strain than the rear skins. This confirms that the foam core plays a major role in energy absorption during loading as the strain is mitigated. This occurs through elastic compression and damage to the core visible from DIC analysis.

- Although the magnitude of rear skin strain from DIC is lower, the spatial strain distribution correlates between front and rear.

- Hybrid composite sandwich panels have demonstrated variations under impact loading due to the localised nature of the impact experiment. Under blast loading, the panel is able to respond in a global manner; hence, both skins and cores are engaged simultaneously.

- DIC data define panel response during blast and are transferable for further analysis as motion of the non-rigid cubicle was successfully removed.

- The finite element model developed successfully predicts the elastic response of hybrid composite sandwich panels under air blast loading.

Acknowledgements The authors would like to thank Dr. Yapa Rajapakse of the Office of Naval Research (N62909-15-1-2004, N00014-08-1151 and N00014-12-1-0403) for supporting Emily Rolfe, Dr. Mark Kelly and Dr. Hari Arora during their PhDs and EPSRC for supporting Emily Rolfe during her $\mathrm{PhD}$. The assistance in preparation for the experiments by Jun Liu was very much appreciated along with the testing opportunity provided by CPNI and the support during the experiments from GOM UK, Slowmo Ltd and DNV GL.

Open Access This article is distributed under the terms of the Creative Commons Attribution 4.0 International License (http://creativecomm ons.org/licenses/by/4.0/), which permits unrestricted use, distribution, 
and reproduction in any medium, provided you give appropriate credit to the original author(s) and the source, provide a link to the Creative Commons license, and indicate if changes were made.

\section{References}

Andrews EW, Moussa NA (2009) Failure mode maps for composite sandwich panels subjected to air blast loading. Int J Impact Eng 36:418-425. https://doi.org/10.1016/j.ijimpeng.2008.08.005

Arora H (2012) Blast loading of fibre reinforced polymer composite structures. Imperial College, London

Arora H, Hooper PA, Dear JP (2011) Dynamic response of full-scale sandwich composite structures subject to air-blast loading. Compos Part A Appl Sci Manuf 42:1651-1662. https://doi.org/10.10 16/j.compositesa.2011.07.018

Arora H, Hooper P, Del LP et al (2012) Modelling the behaviour of composite sandwich structures when subject to air-blast loading. Int J Multiphys 6:199-218. https://doi.org/10.1260/1750-9548.6. 3.199

Arora H, Kelly M, Worley A et al (2014) Compressive strength after blast of sandwich composite materials. Philos Trans R Soc Lond A Math Phys Eng Sci 372:20130212

Benzeggagh ML, Kenane M (1996) Measurement of mixed-mode delamination fracture toughness of unidirectional glass/epoxy composites with mixed-mode bending apparatus. Compos Sci Technol 56:439-449. https://doi.org/10.1016/0266-3538(96)000 $05-\mathrm{X}$

Czél G, Wisnom MR (2013) Demonstration of pseudo-ductility in high performance glass/epoxy composites by hybridisation with thinply carbon prepreg. Compos Part A Appl Sci Manuf 52:23-30. https://doi.org/10.1016/j.compositesa.2013.04.006

Dassault Systèmes (2012) Abaqus 6.12 Documentation, Rhode Island

Enfedaque A, Molina-Aldareguía JM, Gálvez F et al (2010) Effect of glass fiber hybridization on the behavior under impact of woven carbon fiber/epoxy laminates. J Compos Mater 44:3051-3068. https://doi.org/10.1177/0021998310369602

Falzon BG, Apruzzese P (2011a) Numerical analysis of intralaminar failure mechanisms in composite structures. Part I: FE implementation. Compos Struct 93:1039-1046. https://doi.org/10.1016/j.c ompstruct.2010.06.028

Falzon BG, Apruzzese P (2011b) Numerical analysis of intralaminar failure mechanisms in composite structures. Part II: applications. Compos Struct 93:1047-1053. https://doi.org/10.1016/j.compstr uct.2010.06.022

Falzon BG, Liu H, Tan W (2017) Comment on A tensorial based progressive damage model for fiber reinforced polymers. Compos Struct 176:877-882. https://doi.org/10.1016/j.compstruct.2017.0 6.011

Gardner N, Wang E, Kumar P, Shukla A (2012) Blast mitigation in a sandwich composite using graded core and polyurea interlayer. Exp Mech 52:119-133. https://doi.org/10.1007/s11340-011-951 7-9

Kable (2018a) Naval technology: Visby class. https://www.naval-tech nology.com/projects/visby/

Kable (2018b) Naval Technology: Skjold Class Missile Fast Patrol Boats, Norway. http://www.naval-technology.com/projects/skjol d

Kelly M (2016) Comparing the blast tolerance of different composite structures. Imperial College, London

Kelly M, Arora H, Worley A et al (2015) Sandwich panel cores for blast applications: materials and graded density. Exp Mech. https://do i.org/10.1007/s11340-015-0058-5

LeBlanc J, Gardner N, Shukla A (2013) Effect of polyurea coatings on the response of curved E-glass/vinyl ester composite panels to underwater explosive loading. Compos Part B Eng 44:565-574. https://doi.org/10.1016/j.compositesb.2012.02.038

Lim TS, Lee CS, Lee DG (2004) Failure modes of foam core sandwich beams under static and impact loads. J Compos Mater 38:1639-1662. https://doi.org/10.1177/0021998304044760

Liu H, Falzon BG, Tan W (2018) Predicting the compressionafter-impact (CAI) strength of damage-tolerant hybrid unidirectional/woven carbon-fibre reinforced composite laminates. Compos Part A Appl Sci Manuf 105:189-202. https://doi.org/1 0.1016/j.compositesa.2017.11.021

Manders PW, Bader MG (1981) The strength of hybrid glass/carbon fibre composites. J Mater Sci 16:2233-2245. https://doi.org/10.1 007/BF00542386

Murugan R, Ramesh R, Padmanabhan K (2014) Investigation on static and dynamic mechanical properties of epoxy based woven fabric glass/carbon hybrid composite laminates. Proc Eng 97:459-468. https://doi.org/10.1016/j.proeng.2014.12.270

Naresh K, Shankar K, Rao BS, Velmurugan R (2016) Effect of high strain rate on glass/carbon/hybrid fiber reinforced epoxy laminated composites. Compos Part B Eng 100:125-135. https://doi. org/10.1016/j.compositesb.2016.06.007

Pandya KS, Pothnis JR, Ravikumar G, Naik NK (2013) Ballistic impact behavior of hybrid composites. Mater Des 44:128-135. https://d oi.org/10.1016/j.matdes.2012.07.044

Randjbaran E, Zahari R, Abdul Jalil NA, Abang Abdul Majid DL (2014) Hybrid composite laminates reinforced with kevlar/carbon/glass woven fabrics for ballistic impact testing. Sci World J 2014:413753. https://doi.org/10.1155/2014/413753

Reddy PRS, Reddy TS, Mogulanna K et al (2017) Ballistic impact studies on carbon and E-glass fibre based hybrid composite laminates. Proc Eng 173:293-298. https://doi.org/10.1016/J.PROEN G.2016.12.017

Rizov V, Shipsha A, Zenkert D (2005) Indentation study of foam core sandwich composite panels. Compos Struct 69:95-102. https://d oi.org/10.1016/j.compstruct.2004.05.013

Rolfe E, Kelly M, Arora H et al (2017) Failure analysis using X-ray computed tomography of composite sandwich panels subjected to full-scale blast loading. Compos Part B 129:26-40. https://doi. org/10.1016/j.compositesb.2017.07.022

Rolfe E, Kaboglu C, Quinn R et al (2018) High velocity impact and blast loading of composite sandwich panels with novel carbon and glass construction. J Dyn Behav Mater 1-14. https://doi.org/10.1 007/s40870-018-0163-5

Salvi AG, Waas AM, Caliskan A (2008) Energy absorption and damage propagation in $2 \mathrm{D}$ triaxially braided carbon fiber composites: effects of in situ matrix properties. J Mater Sci 43:5168-5184. https://doi.org/10.1007/s10853-008-2684-0

Sevkat E, Liaw B, Delale F, Raju BB (2009) Drop-weight impact of plain-woven hybrid glass-graphite/toughened epoxy composites. Compos Part A Appl Sci Manuf 40:1090-1110. https://doi.org/1 0.1016/J.COMPOSITESA.2009.04.028

Sevkat E, Liaw B, Delale F, Raju BB (2010) Effect of repeated impacts on the response of plain-woven hybrid composites. Compos Part B Eng 41:403-413. https://doi.org/10.1016/J.COMPOSITESB.2 010.01.001

Smith PD, Hetherington JG (1994) Blast and ballistic loading of structures. Butterworth-Heinemann, Oxford

Song JH (2015) Pairing effect and tensile properties of laminated highperformance hybrid composites prepared using carbon/glass and carbon/aramid fibers. Compos Part B Eng 79:61-66. https://doi.o rg/10.1016/j.compositesb.2015.04.015

Swolfs Y, Gorbatikh L, Verpoest I (2014) Fibre hybridisation in polymer composites: a review. Compos Part A Appl Sci Manuf 67:181-200. https://doi.org/10.1016/j.compositesa.2014.08.027

Tan W, Falzon BG, Price M (2015) Predicting the crushing behaviour of composite material using high-fidelity finite element modelling. 
Int J Crashworth 20:60-77. https://doi.org/10.1080/13588265.20 14.972122

Tekalur SA, Shukla A, Shivakumar K (2008) Blast resistance of polyurea based layered composite materials. Compos Struct 84:271-281. https://doi.org/10.1016/j.compstruct.2007.08.008

Vaidya RS, Sun CT (1997) Fracture criterion for notched thin composite laminates. AIAA J 35:311-316. https://doi.org/10.2514/2.93
You Y-J, Park Y-H, Kim H-Y, Park J-S (2007) Hybrid effect on tensile properties of FRP rods with various material compositions. Compos Struct 80:117-122. https://doi.org/10.1016/j.compstruct.200 6.04 .065

Publisher's Note Springer Nature remains neutral with regard to jurisdictional claims in published maps and institutional affiliations. 